\title{
Improvement of Ti Processing through Colloidal Techniques
}

\author{
R. G. Neves ${ }^{1, a}$, J.A.Escribano ${ }^{2, b}$, B. Ferrari ${ }^{2, c}$, E. Gordo ${ }^{1, d}$ \\ and A.J. Sanchez-Herencia ${ }^{2, e}$ \\ ${ }^{1}$ Department of Materials Science and Engineering and Chemical Engineering, University Carlos \\ III of Madrid, Spain \\ ${ }^{2}$ Institute for Ceramic and Glass (ICV - CSIC), Madrid, Spain \\ argneves@ing.uc3m.es; bjescribano@icv.csic.es, 'bferrari@icv.csic.es; 'delena.gordo@uc3m.es;
}

Keywords: Slurries, dispersant, Spray dry, Particle size distribution, Water

\begin{abstract}
The colloid-chemistry control of metallic powders in aqueous slurries is proposed as a way to prepare Ti powders with small particle size for a better pressing behavior through the spray dry process. The chemical-physic behavior of titanium powders with two different particle size distributions dispersed in water has been studied by measuring the zeta potential as a function of $\mathrm{pH}$, and dispersant concentration. The employment of poly-acrylic dispersants allowed the fabrication of stable slurries with solid contents up to 50 vol\% that have been sprayed under different conditions to form agglomerates ranging between 50 and $200 \mu \mathrm{m}$. Conditions were selected to achieve spherical agglomerates formed by a broad distribution of particle sizes that shown excellent flowability. Agglomerates were pressed in a uniaxial die to measure the compressibility, showing an improvement in pressing behavior with respect to powders with bigger particle size. The sintering behavior is also improved, as values of $96 \%$ of the theoretical density were obtained for compacts sintered in vacuum at $1100{ }^{\circ} \mathrm{C}$ for 30 minutes.
\end{abstract}

\section{Introduction}

The processing of Ti by conventional PM, pressing and sintering, presents serious difficulties due to its intrinsic characteristics, like low strain capacity, and his high reactivity [1,2], which leads to low compressibility. In previous works, the authors have employed sintering temperatures ranging between 1250 and $1350{ }^{\circ} \mathrm{C}$, and times as long as 2 or 4 hours, to obtain densities of about $95 \%$ of theoretical $[3,4,5]$. As a consequence of the high temperature and prolonged times the grain size becomes coarse, the content of interstitial elements is high, and the final properties are lower than expected. All these problems could be overcome when reducing the particle size of the starting powders and consequently the sintering temperature. Powders with low particle size are difficult to process by PM techniques as they present poor flowability and pressing curves and stick to die walls. Spray-dry is a common technique employed to transform small powders in granules suitable to flow, fill the die and get pressed without problems. It requires of dispersions of the powders in a liquid media, usually water that are sprayed through a nozzle and dried by a hot air current. The colloidal chemistry of the powders dispersed in water became so a critic aspect to achieve homogenous materials. It has been used for long in ceramics to achieve complex shapes and microstructures [6,7]. The colloidal processing of powders dispersed in water is based on two main factors interconnected. One is the control of the interparticle potentials between particles in order to 
achieve high repulsions, prevent the agglomeration and obtain good dispersions. The other factor to be taken into account is the rheology of the slurries that depends on the level of repulsions of the particles in the media as well as in other variables as solid contents and processing additives. By control the colloid-chemistry of the metallic particles in water, suspensions of pure nickel and nickel-ceramics composites with high solid contents has been obtained [8,9].

In this work the colloidal behavior of fine titanium powders in an aqueous environment is studied, focusing on the surface stability and their correct dispersion, to achieve stables aqueous suspensions. Agglomerates of powders through spray-dry of the suspensions are prepared and its pressing and sintering behavior is reported.

\section{Experimental procedure}

Starting materials were two elemental titanium powders, with different particle size and spherical shape, supplied by AP\&C Inc: Ti45 $\mu \mathrm{m}$ (Ti45) and Ti10 $\mu \mathrm{m}$ (Ti10) grade 1 . The size and morphology were examined by FE-SEM (Hitachi S-4700 microscope Japan). Density, distribution size and specific surface area were measured using a Monosorb Multipycnometer; Mastersizer S Malvern instruments Ltd. and a Monosorb Surface Area from Quantachrome Corporation (USA), respectively. Chemical analyses were carried out with a LECO TCH-600 for oxygen.

Zeta potential $(\zeta)$ of powders in water were measured with a Zeta-Meter 3.0 + (ZETER METER Inc., EEUU). For these measurements, dispersions of Ti powders were prepared with solid contents of $1 \mathrm{wt} \%$ in a $10^{-2} \mathrm{M}$ solution of $\mathrm{KNO}_{3}$ (as inert electrolyte). The $\mathrm{pH}$ was measured with a $\mathrm{pH}$-meter (691 pH Meter from Metrohm), and adjusted by using HTMA (tetra methyl ammonium hydroxide) and diluted $\mathrm{HNO}_{3}$ solutions. The zeta potential was recorded as a function of both the $\mathrm{pH}$ of the suspension and the polyelectrolyte (ammonium polyacrilate, PAA, Mw=2000, Across) content.

The rheological behavior of the suspensions was determined with a HAAKE viscometer Rotovisco RV 20 using a concentric cylinders system (MV2). All the tests were performed in control rate (CR) mode with the following cycle: shear rate ramp from 0 to $450 \mathrm{~s}^{-1}$ in 1 minute, maintaining at $450 \mathrm{~s}^{-1}$ for 1 minute and finally from 450 to $0 \mathrm{~s}^{-1}$ in 1 minute. To evaluate results the shear stress $(\tau)$, in $\mathrm{Pa}$, versus shear rate $(\gamma)$, in $\mathrm{s}^{-1}$ was plotted. These types of graphs are called flow curves.

To produce the spray dried agglomerate powders, slurries of Ti10 with high solid contents (up to 50 vol \%) were fabricated in water using the ammonium polyacrilate as dispersant. After the powder was incorporated to the water with the dispersant, high power ultrasound (400W) were applied to break undesirable agglomerates and the slurries were kept them under stirring for 1 hour. Polyvininyl alcohol (PVA, Aldrich) and polyethylene glycol (PEG, Aldrich) were used as binders. Selected suspensions were spray-dried using a Labplant SD-05 with the main controlled operating parameters such as the temperature at the inlet $\left(220^{\circ} \mathrm{C}\right)$ and at the exhaust $\left(100{ }^{\circ} \mathrm{C}\right)$, the slurry pump rate $(2 \mathrm{l} / \mathrm{h})$, the air flow rate $\left(38 \mathrm{~m}^{3} / \mathrm{h}\right)$, and the atomizing nozzle design were set to provide spherical agglomerates. Both the Ti45 powders and the agglomerates from suspensions of Ti10 powders were processed by pressing and sintering. Pressing was performed in a double effect uniaxial die into cylinders of $16 \mathrm{~mm}$ diameter, using different pressures to obtain the compressibility curve. The green compacts were sintered in vacuum at $1100{ }^{\circ} \mathrm{C}$ for 30 minutes.

The green density was measured using dimensions and sintered density was measured using both dimensions and a Monosorb Multipycnometer (Quantachrome Co.), so that it is possible to obtain data of total, close and open porosity. The oxygen content of sintered samples was measured with a 
LECO TCH-600. Finally the study of microstructure has been examined with optical microscopy (MO).

\section{Results and Discussion}

\section{$\underline{3.1 \text { Characterization of titanium suspensions }}$}

The main features of the titanium powders are reported in table 1 . The Ti10 $\mu$ m powder presents high specific surface area because of the lower mean size. Equivalent spherical diameter calculated from specific surface area is similar to these measures by diffraction techniques indicating that powders have small deviations from the sphere and a smooth surface. Both powders present similar density, very close to the theoretical. Oxygen content was unexpectedly higher in the powder with the low surface area, been this an indicative that Ti10 is treated to prevent the surface oxidation.

Table 1- Characteristics of the investigated powders (laboratory measurements).

\begin{tabular}{|c|c|c|c|c|c|}
\hline \multirow{2}{*}{$\begin{array}{c}\text { Powder } \\
\text { type }\end{array}$} & \multicolumn{2}{|c|}{ 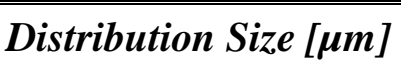 } & \multirow{2}{*}{$\begin{array}{c}\text { Specific surface } \\
\text { area } \\
{\left[\mathrm{m}^{2} / \mathrm{g}\right]}\end{array}$} & \multirow{2}{*}{$\begin{array}{c}\text { Theoretical Density } \\
\qquad\left[\mathrm{g} / \mathrm{cm}^{3}\right]\end{array}$} & \multirow{2}{*}{$\begin{array}{c}O \\
{[w t \%]}\end{array}$} \\
\hline & {$\left[D_{v} 50\right]$} & $d_{B E T}$ & & & \\
\hline $\begin{array}{c}\text { Titanium } \\
45 \mu \mathrm{m}\end{array}$ & 29.21 & $35.0 \pm 0.1$ & $0.04 \pm 0.01$ & $4.4 \pm 0.1$ & 0.336 \\
\hline $\begin{array}{c}\text { Titanium } \\
10 \mu m\end{array}$ & 9.93 & $7.4 \pm 0.1$ & $0.17 \pm 0.01$ & $4.5 \pm 0.1$ & 0.216 \\
\hline
\end{tabular}

The zeta potential has been measured at different $\mathrm{pH}$ in order to determine the surface behavior of the materials and establish the conditions for maximum dispersion Figure 1 a) shows the zeta potential versus $\mathrm{pH}$ for both powders. Ti45 shows an isoelectric point (IEP) around 3.5. Usual values reported on the literature ranges from 3.5 to 8 , as the surfacial charge in titanium oxides is influenced for the particle size and crystallographic phase [10], and for non oxide species in water the IEP is between 3 and 4 [11]. The IEP of the Ti10 was not reported within the measured range. The suspensions of both powders have the same behavior, as they are stabilized at the $\mathrm{pH}$ range between $\mathrm{pH} 6$ and $\mathrm{pH}$ 10, where the zeta potential have a constant value of $-33 \mathrm{mV}$ for the Ti10 and $-22 \mathrm{mV}$ for Ti45. Under these conditions stable slurries with high solid contents could be achieved. But the only control of the $\mathrm{pH}$ is suggested to fluctuations that can destabilize the slurries, thus it is required the use polyelectolyte (PAA) that provide an additional stabilization. In the figure $1 \mathrm{~b}$ ) is shown the zeta potential vs. PAA content for slurries of Ti10 and Ti45 at $\mathrm{pH}=10$. In the case of Ti45, there is no change in the zeta potential indicating that PAA does not attach to the particles surface. In the case Ti10 the zeta potential changes from -25 to $-55 \mathrm{mV}$ indicating that polyelectrolyte has attached to the surface of the particles providing an electrostatic dispersion mechanism. 


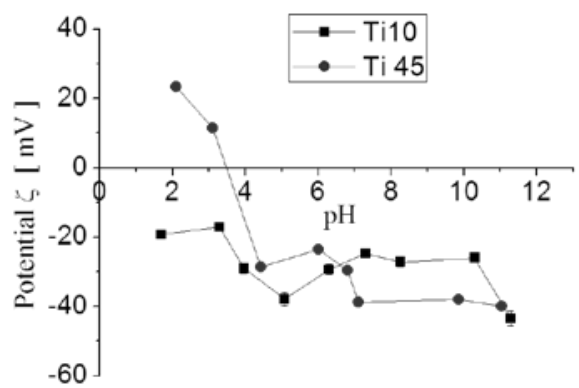

a)

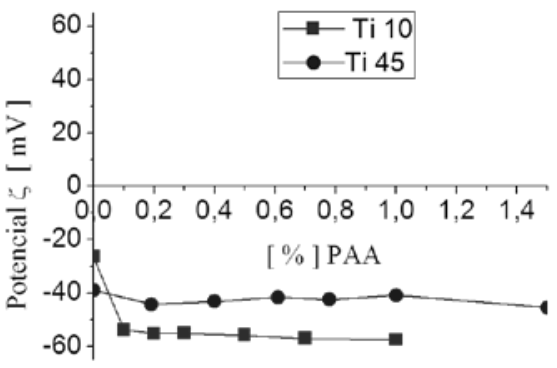

b)

Figure 1- a) Zeta Potential versus $\mathrm{pH}$ of $\mathrm{Ti}_{45}$ and $\mathrm{Ti}_{10}$ b) Zeta Potential as a function of dispersant content of

\subsection{Rheological characterization}

$$
\mathrm{Ti}_{45} \text { and } \mathrm{Ti}_{10}
$$

According to zeta potential measurements, slurries were formulated with $\mathrm{Ti} 10$ at a $\mathrm{pH}=10$ and with $1 \%$ of PAA to ensure a good stability. Figure 2 a) shows flow curves for slurries of Ti10. Both suspensions have not yield stress, but present a trixotropic cycle. It is observed that the viscosity (stress to strain ratio on the flow curves) increases while increasing solid contents. At 50 vol\% viscosity values around $25 \mathrm{mPa} \cdot \mathrm{s}$ are achieved being this data low enough for spray [12]. Figure 2 b) shows flow curves for Ti10 slurries at 50 vol\% of solid content with additions of $2 \%$ of PVA and PEG as binders. Ti10 slurry with $2 \%$ PVA presents higher viscosity values than the same slurry with $2 \%$ of PEG.

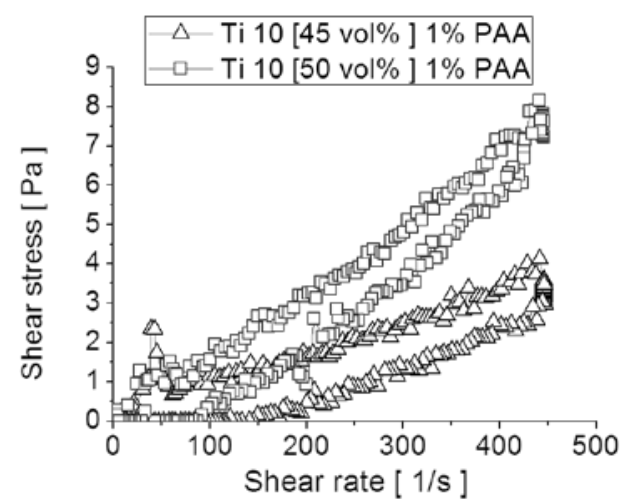

(a)

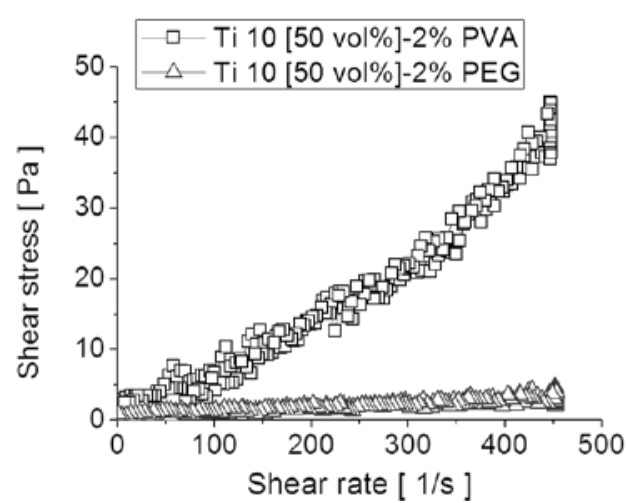

(b)

Figure 2- a) Flow curve for slurries of Ti10 for different solid contents b) Flow curves fo Ti10 slurry with PVA and PEG.

\section{$\underline{3.3 \text { Processing of powders and compacts }}$}

The slurries with solid contents of 50 vol\% and $2 \%$ of binder (PVA and PEG) were spray-dried to obtain the agglomerates, whose morphology was observed by SEM (Figure 3). When PVA is employed as binder, (Figure 3 a), spherical agglomerates with regular shapes and sizes between 50 and $200 \mu \mathrm{m}$ are collected, while the use of PEG (Figure $3 \mathrm{~b}$ ) shows agglomerates with irregular shapes and lower size distribution. Therefore slurries of Ti10 at $\mathrm{pH}=10,1 \%$ of PAA, solid contents of 50 vol\% and 2\% PVA provide the spray-dried powders with the best features for pressing and sintering. 


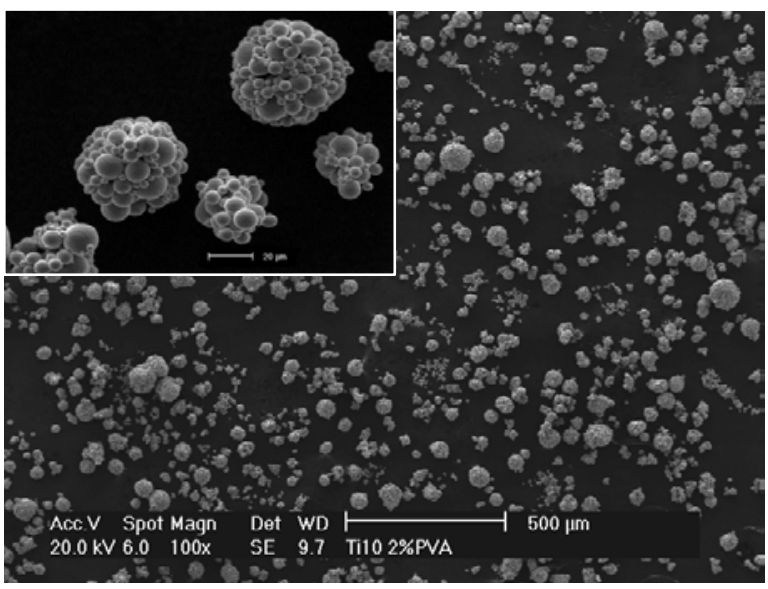

(a)

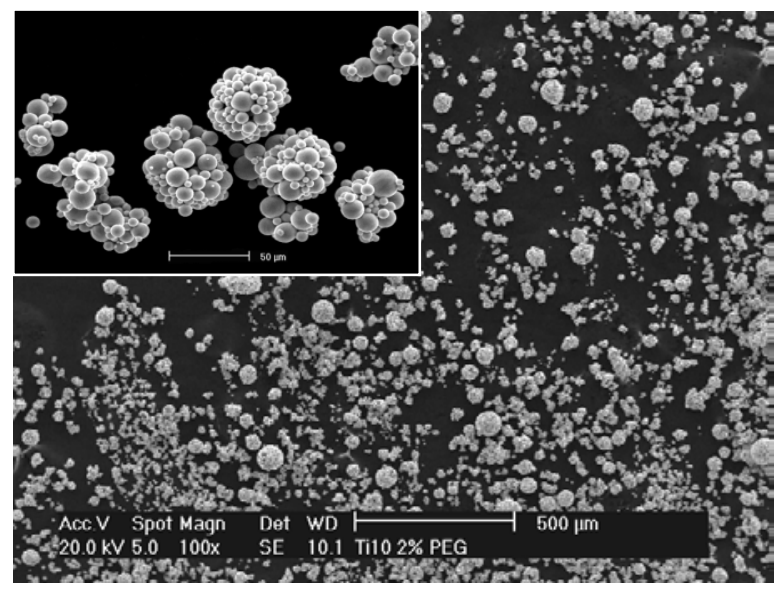

(b)

Figure 3- Granules obtained by Spray dry process for Ti10 $\mu$ m [50\% vol] with: a) 2\% PVA b) 2\% PEG. The compressibility of two powders, Ti45 and spray-dried Ti10 (as shown on figure 3.a), was studied by compacting samples at different pressures. Figure 4 shows the compressibility curves for these two powders. It can be observed that green density is higher for pressed Ti10 agglomerates than for Ti45 powder. This is due to the better particle size distribution and close packing that is achieved by employing the agglomerates. Once the pressure (600 MPa) was selected, samples were

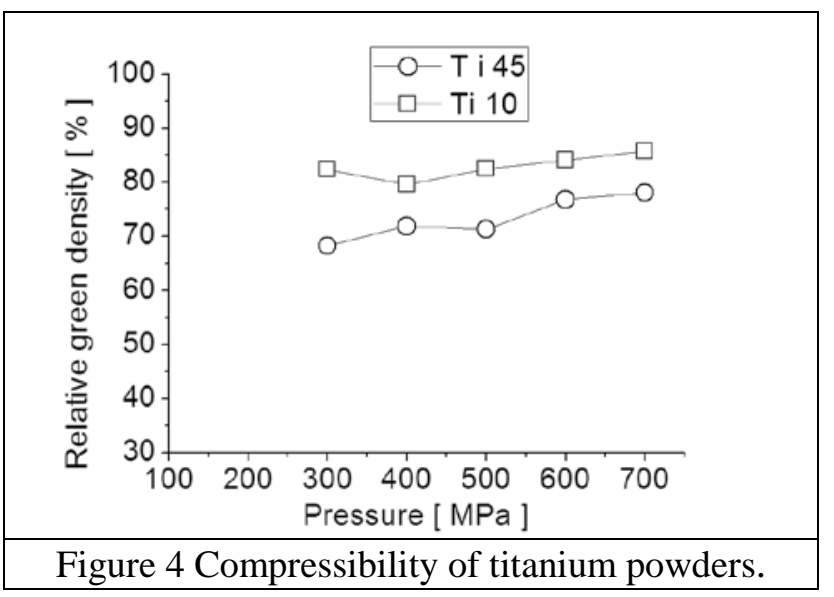
pressed and sintered at $1100{ }^{\circ} \mathrm{C}$ for 30 minutes. Table 2 shows values of density and porosity for sintered samples. It is observed that samples from spray-dried powders show a lower open porosity while maintain a similar closed porosity than Ti45. After sintering process, it is also observed a slightly oxygen content increment with respect to the values of the as-received powders. Powder with a high specific surface area presents higher oxygen content. Oxygen comes from all the processing steps and remains within the sample even after sintering under high vacuum. Figure 5 shows the microstructure of sintered materials, formed in both cases by equiaxial grains of alpha phase. It is clear that the grain size of Ti45 (Figure $5 a$ ) is bigger than Ti10 (Figure 5b). In order to confirm these data, it is calculated the mean grain size and it is observed a reduction of $40 \%$. The porosity is higher and uniformly distributed in the case of Ti45 (small round dots in each grain). These microstructures are in agreement with the data of Table 2, and permit to confirm that the smaller particle size of the powder particles improves the sintering process as the porosity is reduced when compared to Ti45 $\mu \mathrm{m}$.

Table 2- Characteristics of sintered materials.

\begin{tabular}{||c||c|c|c|c|c|c|c||}
\hline \hline & $\rho_{\text {Pycnometer }}$ & $\rho_{\text {Dimensions }}$ & $\boldsymbol{P}_{\text {total }}$ & $\boldsymbol{P}_{\text {open }}$ & $\boldsymbol{P}_{\text {closed }}$ & O [wt\%] & $\begin{array}{c}\text { Mean } \\
\text { grain size } \\
\text { [ } \boldsymbol{\mu m} \text { ] }\end{array}$ \\
\hline $\begin{array}{c}\text { Ti45 } \\
\boldsymbol{\mu m}\end{array}$ & $95.69 \pm 0.001$ & $82.76 \pm 0.01$ & 17.24 & 12.93 & 4.31 & 0.66 & 100 \\
\hline $\begin{array}{c}\mathbf{T i 1 0} \\
\boldsymbol{\mu m}\end{array}$ & $96.02 \pm 0.001$ & $95.18 \pm 0.01$ & 4.82 & 0.84 & 3.98 & 0.43 & 60 \\
\hline
\end{tabular}




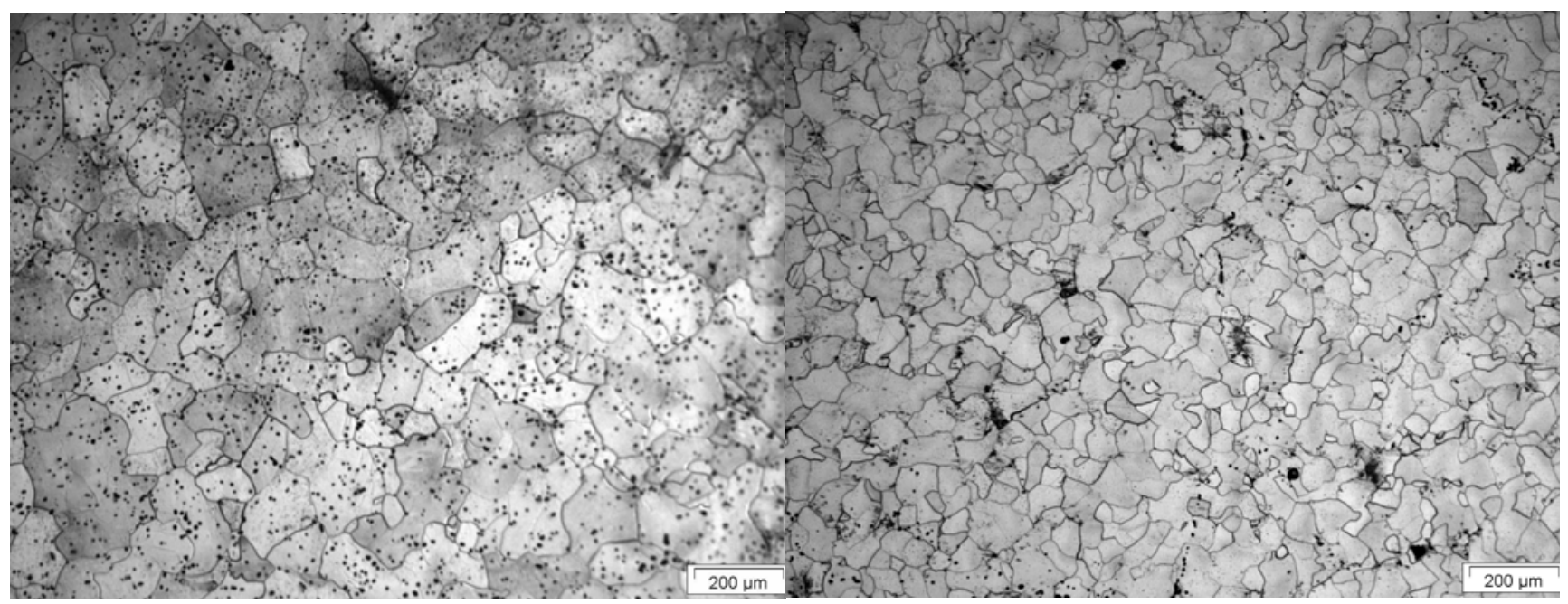

(a)

(b)

Figure 5. Microstructure of sintered samples obtained from (a) Ti45 as received powders and (b)

\section{Summary and Conclusions}

Ti10 spray-dried powders, pressed and sintered in similar conditions.

- By using a polyacrilate as dispersant, slurries of titanium particles with average particle size of 10 $\mu \mathrm{m}$ have been fabricated with a solid content up to $50 \mathrm{vol} \%$.

- Controlling the spray drying parameter spherical agglomerates with a homogenous distribution of particles were fabricated by adding $2 \mathrm{wt} \%$ of PVA to the stable slurries. Sizes of sprayed agglomerates ranges between 50 and $200 \mu \mathrm{m}$.

- The compressibility of agglomerates from suspensions is better than dense powders of 45 microns, leading to higher green densities in all the pressures range studied.

- The sintering behavior has been also improved showing relative density values around $96 \%$ with relatively low temperature $1100{ }^{\circ} \mathrm{C}$. Therefore, it seem clear an improvement of feasibility of the $10 \mu \mathrm{m}$ powder pressing leading to structure with a lower grain size. This work allows a free way for colloidal processing of titanium powders which allows compaction of complex shapes and homogenous mixtures of powders for future works.

\section{Acknowledgements}

The authors want to acknowledgement the financial support from Spanish Ministry of Science and innovation through the Project MAT 2009-14448-C01, and MAT 2009-14448-C02.

\section{References}

[1] I.J. Polmear, Light Alloys. From Traditional Alloys to Nanocrystals, 4 th ed., ButterworthHeinemann, 2006.

[2] C. Leyems and M. Peters, Titanium and titanium Alloys. Fundamentals and Applications, Wiley-VCH, 2003.

[3] P. G. Esteban, L. Bolzoni, E. M. Ruiz-Navas and E. Gordo, PM processing and characterization of Ti-7Fe low cost titanium alloys, Powder Metallurgy, 3, 54 (2011) 242-252.

[4] P.G. Esteban, E.M. Ruiz-Navas, E. Gordo, Influence of Fe content and particle size the on the processing and mechanical properties of low-cost Ti-xFe alloys, Materials Science and Engineering A 527 (2010) 5664-5669.

[5] W. Wei, Y. Liu, K. Zhou, B. Huang, Powder Metall. 46 (2003) 246-250.

[6] Hirata, D.Y, Colloidal processing. Processo colloidale Ceramurgia 25, (1995) 271-276. 
[7] Sanchez-Herencia, A.J. Water based Colloidal Processing of Ceramic Laminates, Key Eng. Mat. 333 (2007) 39-48.

[8] Ferrari, B, Sanchez-Herencia, A.J., Moreno, R., Porous Nickel Coatings on Steel Tubes Formed by Aqueous Colloidal Processing, Adv. Eng. Mater. 4 (2002) 690-4.

[9] Gonzalo-Juan, I., Ferrari, B., Colomer, M.T., Sanchez-Herencia, A. J., Colloidal processing and sintering of porous percolative Ni-YSZ layers, J. Mem. Sci., 58 (2010) 3014-21.

[10] Suttiponparnit, K., Jiang, J., Sahu, M., Suvachittanont, S., Charinpanitkul, T.and Biswas, P., Role of Surface Area, Primary Particle Size, and Crystal Phase on Titanium Dioxide Nanoparticle Dispersion Properties, Nanoscale Res. Lett. 6 (2011) 27.

[11] Yeh, C.-H. \& Hon, M.-H. Dispersion and stabilization of aqueous TiC suspension. Ceramics International 21, (1995) 65-68.

[12] G. Bertrand, P. Roy, C. Filiatre, C. Coddet, Spray-dried ceramic powders: A quantitative correlation between slurry characteristics and shapes of the granules. Chemical Engineering Science 60 (2005) 95-102. 